\title{
Potential for the use of information systems in the management of construction waste
}

\author{
Aleksandr Aleksanin ${ }^{1, *}$ \\ ${ }^{1}$ Moscow State University of Civil Engineering, Yaroslavskoe shosse, 26, Moscow, 129337, Russia
}

\begin{abstract}
At the present stage of the development of the construction industry, based on the principles of sustainable development, special attention should be paid to the formation of construction waste. Reserves for improving the level of efficiency of waste management can be found in the application of modern information technologies and their adaptation to resource-saving problems. The use of information systems is advisable at all stages of the life cycle of a building. Today, the technology of building information modeling (BIM) is actively developing, which can significantly reduce the amount of waste generation in construction. This is possible with its implementation at the design stage, in order to avoid irrational design decisions, collisions, etc. Information systems for data transmission allow rapid exchange of information between project participants, promptly warn about changes in space-planning decisions, materials, structures and equipment. At the stage of operation, in the presence of the information model of the building, it is possible to create a planning system for the organization of works of major overhaul or reconstruction. This article also proposes a description of the functions that an information system must have aimed at coordinating the management of construction waste in the region.
\end{abstract}

\section{Introduction}

In each city, regular work is carried out aimed at the development of urban areas, increasing the level of comfort of the population. These processes are directly related to the construction of new buildings and structures and demolition of old ones that do not meet modern requirements for safety and comfort. Large-scale work is carried out to implement one of the goals of sustainable development "Ensuring openness, security, vitality and environmental sustainability of cities and settlements." This is due to both population growth in cities and the fact that existing building blocks may lack, for example, the necessary social infrastructure or there is very poor transport accessibility. The construction of new buildings and structures in cities can also be limited by the lack of free space. To solve this problem it is possible at the expense of development of industrial territories which are not used in connection with ecological requirements or inefficiency of manufacture. Renovation of industrial territories has the potential to improve the living standards of the population. The development of these territories will allow creating green park areas, social infrastructure

\footnotetext{
*Corresponding author: aleks08007@mail.ru
} 
facilities, residential quarters [1-5].

All the above works aimed at achieving the goals of sustainable development lead to the formation of a significant amount of construction waste, the management of which is one of the most urgent in the construction industry. Reserves for improving the efficiency of coordination and management of waste streams can be found in the application of modern information technologies and their adaptation to resource-saving problems. The use of information systems is advisable at all stages of the life cycle of the construction site [6-9].

\section{Theoretical Basis}

We can distinguish three main stages of the life cycle of an object: the creation of an object; operation of the facility; object liquidation $[10,11]$.

The stage "creation of an object" combines the phases of a feasibility study, design, construction, production of building materials. At this stage, to prevent the formation of "excess" volumes of construction waste during construction, it is advisable to use the toolkit of information modeling of buildings. This will create accurate working drawings and specifications with the correct volumes of materials, which, if necessary, can be quickly and error-free counted. The accuracy of working drawings, the consideration of external factors, as well as the speed of information exchange between the designer and the contractor will avoid situations where builders have to work with a deviation from the project, and then redo the work already done after new input from the designer. Information modeling will also avoid collisions already in the design phase. For example, when the designer provides an opening for mounting technological equipment that is smaller than required, dimensions. In the period of direct construction of the facility, the reduction in the share of construction waste is possible due to the presence of a visual 3D model and its binding to time, that is, 4D modeling. This will allow to manage the construction and schedule the receipt of construction materials, structures and equipment, not allowing their order in larger than required volumes. The availability of the information model of the building allows you to rationally and transparently spend various types of resources [12-16].

The stage "operation of the facility" combines the phases of production of works to improve the energy efficiency of the facility, maintenance, current and capital repair, reconstruction. Creation of the operational model of the building provides timely routine maintenance and more accurate planning of the organization of work of major overhaul or reconstruction, which may be associated, including with dismantling.

The "object liquidation" phase includes the phases of demolition and demolition of the building, disposal of construction and demolition waste, recycling of construction and demolition waste. The reserve of efficiency of management of construction waste at this stage consists in the organization of a single centralized control system for construction waste. One of the options for its construction can be the implementation of projects to create specialized logistics centers, the main activity of which will be aimed at regulating the processes of handling construction waste.

Depending on the level of development of the management of construction waste in the region, it is proposed to create one of two types of logistics centers: complex or information [17]. Complex logistics centers should be located at the intersection of major transport highways and in regions where construction of facilities is most intensive, demolition of old structures that do not meet modern human needs is carried out. At the same time, there must be a shortage of waste processing enterprises in the region, otherwise it will not be possible to ensure the full utilization of new capacities within the logistics center. The organization of information logistics centers is advisable in regions where there is already a sufficient number of enterprises for processing construction waste, but there is no interaction between participants in the process of waste management. 
To create an effective model of waste management arising from the construction and demolition of structures, it is necessary to develop a mechanism for the formation and flow of information flows between all participants in the process. Fulfillment of this condition will lead to optimization of traffic flows, a clear analysis of the characteristics and volumes of construction waste, timely provision of up-to-date information of construction and installation organizations, transport companies, recycling and demolition facilities, and secondary resource consumers. To do this, it is necessary to create a single information system to support all processes for managing the flow of generated waste [18-21].

\section{Results and Discussion}

Effective functioning of the majority of modern technological processes is provided due to their high-quality information support. Within the framework of this article, a structural diagram of the information system for managing construction waste in the region is proposed. The proposed system should become a means of organizing a single information space for ensuring effective communications between the territorial and sectoral logistics centers and other participants in the construction industry. In addition, the program will be a source of up-to-date statistical information reflecting the real state of affairs in the sphere of construction waste management. Figure 1 shows the scheme for using the proposed scheme by the participants in the waste management process of construction production.

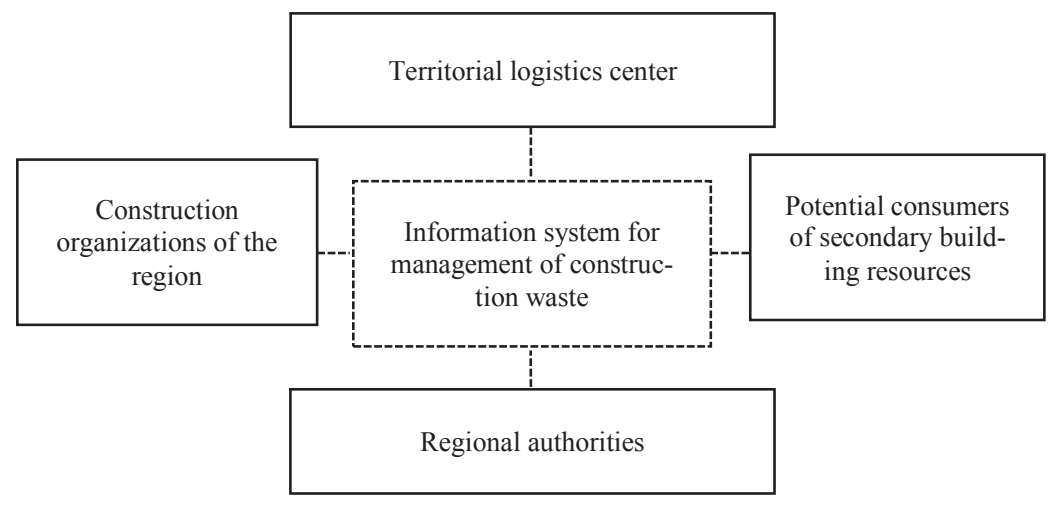

Fig. 1. Scheme of using the information system for management of construction waste in the region.

The information system should include two main databases. The first database contains information on the buildings and facilities of the region, the second database offers a list of processing points and landfills for the disposal of construction waste. The database of buildings and structures consists of objects that are planned to be demolished, repaired, reconstructed, as well as information on the objects under construction. The block diagram of the program modules of the information system is presented in Figure 2.

In the information system, each object must be identified at its location. Having chosen a particular building or structure, the user should be able to get acquainted with the information on the date of commissioning it and about the planned date of repair work (reconstruction, demolition). To calculate the potential volumes of building waste, the table should contain the main technical and economic indicators of the building, the material of bearing and enclosing structures, as well as contact details of the organization that will be engaged in the production of works.

For a particular building object, the program specifies the following information:

- list of generated waste types;

- volumes of education for each type of waste; 
- the hazard class of each waste;

- code according to the classification catalog of waste;

- volumes of waste accumulation at the site;

- characteristics of the place and time of temporary storage of waste;

- data on the frequency of waste disposal from the site;

- characteristics of vehicles used for the export of waste;

- information on the organization that carries out the export of waste;

- the addresses of the objects to which the movement of the waste is planned.

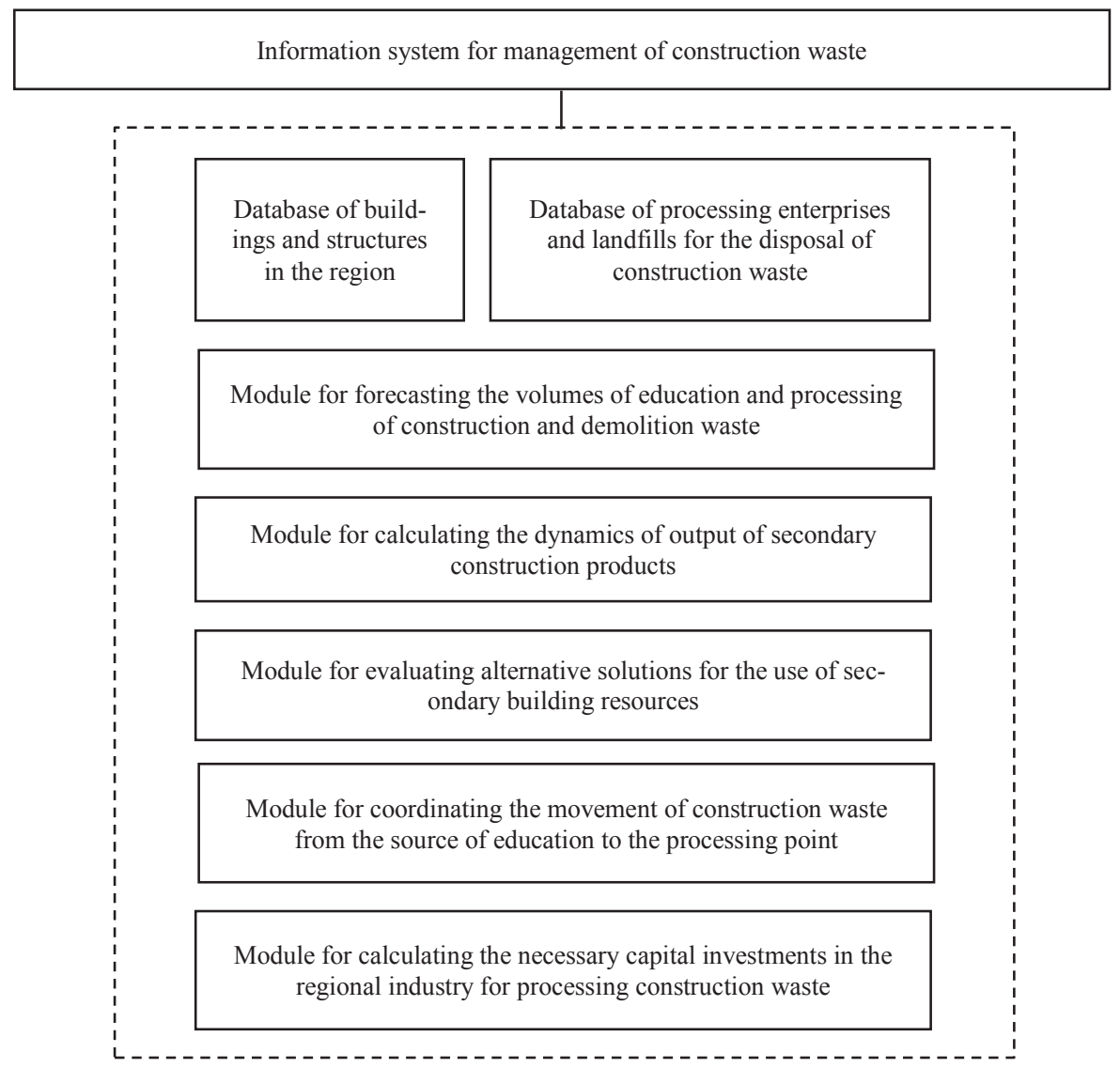

Fig. 2. Block diagram of the information system modules.

To ensure optimal transport of construction and demolition waste, it is necessary to build individual route schemes. When selecting the item "route scheme of waste disposal" in the data list, a corresponding table should appear which indicates the type and volume of construction and demolition waste, the brand and average speed of the vehicle, the distance to the facility, the time of delivery of the goods to the landfill or processing plant, interactive route map.

The database of points for processing and disposal of waste contains general information on the relevant enterprises in the region, namely their addresses, commissioning dates, information on design capacity and required licenses. When choosing a particular enterprise, a table should be opened with information on the type and amount of waste received for processing, the date and time of acceptance, as well as the end of waste processing, the amount and type of the secondary resource received, and the available capacity 
for waste processing.

\section{Conclusions}

Informatization of the stages of the life cycle of the construction site will allow to optimize the management schemes for the waste streams of the construction industry and to reduce the volumes of their formation. It is especially important that the basis for achieving the result of resource conservation can be laid already at the design stage. The information system proposed in the article will allow obtaining information about planned works on repair, reconstruction, demolition and construction of buildings and structures in the region for a promising period. The database with the specification of technical and economic indicators of the facilities will make it possible to make forecasts of the formation of construction waste for the billing period.

\section{References}

1. Y. Wu, J. Luo, X. Zhang, M. Skitmore. Habitat International, 56, 42 (2016)

2. C. Micovits, W. Rauch, M. Kleidorfer. Procedia Engineering, 70, 1147 (2014)

3. A. Aleksanin, S. Sborshikov. MATEC Web of Conferences, 86, 05013 (2016)

4. A. Aleksanin. Industrial and Civil Engineering, 9, 77 (2017)

5. U. Pupphachai, C. Zuidema. Ecological Indicators, 72, 784 (2017)

6. Y. Zharov. Industrial and Civil Engineering, 5, 69 (2013)

7. Y. Zharov. Scientific review, 10-2, 242 (2015)

8. J. Cheng, Q. Lu, M. Phil. Journal of Information Technology in Construction, 20, 442 (2015)

9. X. Ge, P. Livesey, J. Wang, S. Huang, X. He, C. Zhang. Visualization in Engineering, 5, 13 (2017)

10. A. Aleksanin. The Bulletin of BSTU named after V.G. Shukhov, 7, 28 (2017)

11. S. Sborshikov. Scientific review, 2, 183 (2009)

12. Z. Liu, M. Osmani, P. Demian, A. Baldwin. Automation in Construction, 59, 1 (2015)

13. J. Wang, Z. Li, V. Tam. Journal of Cleaner Production, 92, 237 (2015)

14. Z. Wu, A. Yu, L. Shen, G. Liu. Waste Management, 34, 1683 (2014)

15. A. Aleksanin. Scientific review, 5, 12 (2017)

16. S. Sborshikov, N. Lazareva. Vestnik MGSU, 11, 178 (2015)

17. A. Aleksanin, S. Sborshikov. Industrial and Civil Engineering, 2, 66 (2013)

18. A. Subbotin, S. Sborshikov, N. Lazareva. Vestnik MGSU, 3, 247 (2014)

19. S. Sborshikov, N. Lazareva, Y. Zharov. Vestnik MGSU, 6, 165 (2014)

20. J. Cheng, L. Ma. Waste Management, 33, 1539 (2013)

21. A. Pustovgar, A. Adamtsevich, L. Shilova, Advances in Intelligent Systems and Computing, 692, 608 (2018) 